\title{
1 Molecular and cell biological analysis of SwrB in Bacillus subtilis
}

2

3 Andrew M. Phillips ${ }^{1}$, Sandra Sanchez ${ }^{1}$, Tatyana A. Sysoeva ${ }^{2}$, Briana M. Burton ${ }^{3}$, and Daniel B.

4 Kearns $^{1 *}$

5 1Department of Biology, Indiana University, Bloomington IN 47408

6 2Department of Microbiology, University of Alabama, Huntsville, AL 35899

7 3Department of Bacteriology, University of Wisconsin Madison, Madison WI 53706.

$8 \quad$ dbkearns@indiana.edu

$9 \quad 1-812-856-2523$

10

11

12

13

14

15

16

17

28 Keywords: swarming, type III secretion, T3SS, SwrA, SwrB, motility, flagella, PhoA, FlgW, Flk 


\section{ABSTRACT}

Swarming motility is flagellar-mediated movement over a solid surface and Bacillus subtilis cells require an increase in flagellar density to swarm. SwrB is a protein of unknown function required for swarming that is necessary to increase the number of flagellar hooks but not basal bodies. Previous work suggested that SwrB activates flagellar type III secretion but the mechanism by which it might perform this function is unknown. Here we show that SwrB likely acts sub-stoichiometrically as it localizes as puncta at the membrane in numbers fewer than that of flagellar basal bodies. Moreover the action of SwrB is likely transient as puncta of SwrB were not dependent on the presence of the basal bodies and rarely co-localized with flagellar hooks. Random mutagenesis of the SwrB sequence found that a histidine within the transmembrane segment was conditionally required for activity and punctate localization. Finally, three hydrophobic residues that precede a cytoplasmic domain of poor conservation abolished SwrB activity when mutated and caused aberrant migration during electrophoresis. Our data are consistent with a model in which SwrB interacts with the flagellum, changes conformation to activate type III secretion, and departs. 


\section{IMPORTANCE}

50 Type III secretion systems (T3SS) are elaborate nanomachines that form the core of the bacterial

51 flagellum and injectisome of pathogens. The machines not only secrete proteins like virulence factors

52 but also secrete the structural components for their own assembly. Moroever, proper construction

53 requires complex regulation to ensure that the parts are roughly secreted in the order in which they

54 are assembled. Here we explore a poorly understood activator the flagellar T3SS activation in

55 Bacillus subtilis called SwrB. To aid mechanistic understanding, we determine the rules for

56 subcellular punctate localization, the topology with respect to the membrane, and critical residues

57 required for SwrB function. 


\section{INTRODUCTION}

Ancestral strains of Bacillus subtilis swim in liquid environments and swarm over solid surfaces

by synthesizing and rotating flagella (1). Swarming in B. subtilis differs from swimming in at least three ways. First, swarming requires the quorum-activated synthesis and secretion of a lipopeptide surfactant to reduce surface tension and create a thin layer of fluid in which to move (2-5). Second, flagella require a greater amount of torque to swarm (6). Third, the rate of de novo flagellar synthesis during growth must increase so that the number of flagella on the cell surface exceeds a critical threshold (7-10). Two proteins of poorly understood function, SwrA and SwrB, are required to increase flagellar number. SwrA, is the soluble cytoplasmic master activator of flagellar biosynthesis, which in conjunction with the DNA binding transcription factor DegU, is required to activate the expression of flagellar biosynthesis genes $(8,11-15)$. SwrB, is a single-pass transmembrane protein

that increases flagellar number post-transcriptionally $(8,16-17)$. The mechanism of SwrB is poorly understood but genetic evidence suggests that it activates the type III secretion system within the flagellar basal body for the export and assembly of extracellular components.

Flagellar assembly is complex and involves a large number of proteins that must be assembled in a sequential order. The first stage of flagellar assembly is the construction of the basal body in which a protein FliF surrounds and houses a type III protein secretion system (18-20). The basal body is completed by docking of the cytoplasmic C-ring, a cylinder of proteins that contains the rotor for flagellar rotation (21-23). Next, the flagellar type III secretion system exports proteins for the assembly of the axle-like flagellar rod that transits the cell envelope, and the flexible hook that functions as a universal joint (24-26). Once the rod-hook complex achieves a particular length, the secretion system changes specificity and secretes proteins to assemble the long helical flagellar filament (27-32). The completed flagellar structure rotates to act as a propeller and push cells 
$82 \mathrm{rod}$ and hook are encoded by the long, 32 gene, $27 \mathrm{~kb}$ fla/che operon that is activated by SwrA/DegU $83(8,13,33-36)$.

The most distal genes of the fla/che operon encode SigD, an alternative sigma factor that directs expression of a regulon that includes genes required for filament assembly, and SwrB, a protein that enhances SigD activity $(8,16,35,37-39)$. To determine how SwrB activates SigD, spontaneous suppressors were isolated that restored swarming to a swrB mutant (17). Some suppressor mutations were found in the rotor protein FliG that increased C-ring stability, while other suppressors were shown to increase translation of FliP, a core component of the flagellar type III secretion system $(17,19,40-41)$. It was proposed that SwrB acted as a chaperone to aid assembly of the flagellar basal body which would in turn activate flagellar type III secretion, perhaps by a conformational change propagated through FliF to FliP (17). Accordingly, SwrB-mediated activation of type III secretion would enhance SigD activity by export of its cognate anti-sigma factor antagonist,

FlgM $(17,42-45)$. The mechanism by which SwrB promotes basal body assembly or activates the flagellar secretion system is unknown.

Here we explore properties of the SwrB protein to inform the mechanism by which activates and that the puncta neither require, nor strictly co-localize with, flagella. Selection for loss-of-function mutations revealed that a charged residue within the transmembrane domain of SwrB was required for punctate localization, and that localization was conditionally required for SwrB activity. Finally, the mutations that most severely impaired SwrB function changed residues at the junction between the transmembrane helix and the large cytoplasmic C-terminus and conferred anomalous mobility in SDS-PAGE. The data are consistent with a model in which SwrB co-localizes with flagella in a manner that is both early and transient, and that a conformational change is likely important for SwrB activity. 
bioRxiv preprint doi: https://doi.org/10.1101/2021.04.30.442225; this version posted May 1, 2021. The copyright holder for this preprint (which was not certified by peer review) is the author/funder. All rights reserved. No reuse allowed without permission. 


\section{RESULTS}

SwrB localizes as puncta at the membrane independent of flagellar components. SwrB is predicted to be a single-pass transmembrane protein that activates the flagellar type III secretion system, but the mechanism of SwrB is unknown (17). A cell biological approach was undertaken to determine SwrB localization. To generate a functional fluorescent fusion to SwrB protein, we took advantage of the fact that cells mutated for swrB were defective for swarming motility (Fig 1A) and that swarming can be rescued by complementation when the swrB gene was cloned downstream of the $P_{\text {fla/che }}$ promoter and inserted at an ectopic site in the chromosome (Fig 1B) (2). Next, an unstructured linker domain and the gene encoding yellow fluorescent protein YFP were fused to the C-terminus of the swrB gene within the complementation construct, and the construct was introduced to a cell mutated for swrB at the native site. Swarming motility was restored to wild type levels when the SwrB-YFP fluorescent fusion construct was expressed in the swrB mutant (Fig 1B). We conclude that the SwrB-YFP fluorescent was functional for SwrB activity.

When observed by fluorescence microscopy, the SwrB-YFP fusion formed faint puncta at the cell membrane reminiscent of the punctate localization of flagellar basal bodies (9) (Fig 2). To determine the relative localization of SwrB and flagella, a linker and green fluorescent protein (GFP) was translationally fused to the C-terminus of SwrB at the native swrB locus in a strain that also expressed a variant of the flagellar hook protein $\mathrm{FlgE}\left(\mathrm{FlgE}^{\top 123 \mathrm{C}}\right)$ capable of being labeled with a maleimide reactive-fluorescent dye (46). Fluorescence microscopy indicated that there were fewer SwrB puncta than flagellar hook puncta per cell such that that if SwrB co-localized with flagella, SwrB was only present at a subpopulation of machines (Fig 3). Moreover, while some SwrB puncta appeared to co-localize with hook puncta (Fig 3, open caret) the majority did not (Fig 3, closed caret), suggesting that co-localization was rare. Finally, SwrB puncta were observed in strains mutated for the flagellar basal body baseplate protein FliF (encoded by fliF), or mutated for either flagellar type III secretion system protein FlhA or FliP (encoded by flhA and fliP, respectively) (Fig 2). We conclude 
that SwrB punctate localization is independent of even the earliest components of flagellar assembly (20). We infer that flagellar secretion in a way that either does not require SwrB interaction with the flagellum, or that SwrB co-localizes with flagella at an early step prior to flagellar hook assembly and in a manner that is likely transient.

The large C-terminus of SwrB is intracellular. Primary sequence analysis of SwrB indicates that it is a 167 amino acid protein with a single predicted $\mathrm{N}$-terminal transmembrane domain consistent with a Sec-dependent signal sequence (47-50). Models of SwrB mechanism would be aided by an understanding of its membrane topology. One way of determining membrane topology is by generating fusions of the $E$. coli $\beta$-galactosidase LacZ to different regions of the protein of interest. Fusions that display $\beta$-galactosidase activity indicate regions of the protein that reside in the cytoplasm because LacZ is only functional in the reducing environment of the cytoplasm (51). To validate topology-dependent LacZ activity in B. subtilis, the gene encoding LacZ (lacZ) from E. coli was codon optimized for $B$. subtilis and expressed from an IPTG-inducible promoter, either in the cytoplasm ( $\mathrm{no}^{\mathrm{TM}}{ }_{\text {-LacZ) }}$ or in the extracellular environment by fusion to the $\mathrm{N}$-terminal transmembrane segment of the $B$. subtilis flagellar stator protein MotB (MotB ${ }^{\mathrm{TM}}$-LacZ) (52-55). Colonies inoculated on plates containing IPTG and the chromogenic substrate 5-bromo-4-chloro-3-inolyl- $\beta$-Dgalactopyranoside (X-gal) were blue when expressing LacZ in the cytoplasm (Fig 4A). By contrast, the colonies were pale when expressing the fusion to MotB, a reduced activity consistent with the known extracellular topology of MotB C-terminal domain and a failure of LacZ to function extracellularly (Fig 4A). Finally, sxpression of a fusion of the $\mathrm{N}$-terminal transmembrane segment from SwrB to LacZ (SwrB ${ }^{\mathrm{TM}}$-LacZ) produced blue colonies suggesting an opposite orientation to that of MotB (Fig 4A). We infer that the C-terminal domain of SwrB is cytoplasmic.

Another way to determine membrane topology is by generating fusions of the E. coli gene phoA, encoding the alkaline phosphatase PhoA, to different regions of the protein of interest. Fusions 
159 that display alkaline phosphatase activity indicate regions of the protein that extend outside the

cytoplasm because PhoA is only functional in the oxidizing external environment (56-57). PhoA

fusions are not commonly used directly in B. subtilis however, perhaps because wild type colonies have inherent phosphatase activity during vegetative growth that is further induced upon starvation (58-64). Consistent with a basal level of background phosphatase activity, wild type colonies turned blue on media containing the chromogenic alkaline phosphate substrate 5-bromo-4-chloro-3-indolylphosphate $(\mathrm{X}-\mathrm{P})$. Cells simultaneously mutated for two endogenous alkaline phosphates, PhoA and PhoB (both phylogenetically unrelated to the E. coli PhoA protein) (65-66), were white on the same media however, suggesting that pho $A$ phoB double mutants would be a good starting background for PhoA fusion analysis (Fig 4B). Next, the phoA gene from E. coli was codon optimized for expression in B. subtilis, expressed from an IPTG-inducible promoter, either in the cytoplasm (no $\left.{ }^{\mathrm{TM}}-\mathrm{PhoA}\right)$ or in the extracellular environment by fusion to the $\mathrm{N}$-terminal transmembrane segment of $B$. subtilis MotB (MotB $\left.{ }^{T M}-\mathrm{PhoA}\right)$. In the phoA phoB background and the presence of inducer, colonies expressing the no $^{T M}$-PhoA fusion in the cytoplasm were white and colonies expressing the MotB ${ }^{T M}$-PhoA were blue, again consistent with known topology (Fig 4B). Expression of a fusion of the $\mathrm{N}$-terminal transmembrane segment from SwrB to PhoA (SwrB $\left.{ }^{\mathrm{TM}}-\mathrm{PhoA}\right)$ produced colonies that were pale after induction, again suggesting a topology opposite to that of motB (Fig 4B). We conclude that SwrB is a single-pass transmembrane protein in which the C-terminal domain, comprising the majority of the protein, is cytoplasmic.

Residues required for SwrB function. To further explore the mechanism of SwrB, a forward genetic approach was undertaken to identify residues required for SwrB function. A screen was devised based on the observation that mutation of $s w r B$ abolishes $\sigma^{\mathrm{D}}$-dependent gene expression in the absence of the master activator SwrA, and gene expression can be rescued by introduction of a functional swrB complementation construct (8,16-17) (Fig 5). Next, the swrB gene was mutagenized 
by polymerase chain reaction (PCR) amplification with an error-prone polymerase and the amplicon

was cloned downstream of the $P_{\text {flache }}$ promoter between the arms of the amyE gene (amyE:: $P_{\text {flache }}{ }^{-}$ $\left.s w r B^{m u t}\right)$. The clones were then pooled and transformed into a swrA swrB strain containing a $\sigma^{D_{-}}$ dependent reporter in which the promoter for the hag gene $\left(P_{h a g}\right)$ was transcriptionally fused to the lac $Z$ gene encoding $\beta$-galactosidase. Finally, the transformants were plated on media containing the chromogenic substrate X-gal such that colonies containing loss-of-function mutations in the swrB gene would fail to complement $\sigma^{\mathrm{D}}$-dependent gene expression and confer a white colony phenotype.

Over 4000 transformants were screened and 69 mutants with a white colony phenotype were isolated as SwrB ${ }^{\text {mut }}$ alleles. Sequencing of the complementation constructs indicated that many of the mutants contained truncations (nonsense or frameshift mutations), multiple mutations, or defects in the $P_{\text {flache }}$ promoter, and these mutant classes were discarded. Ten alleles contained single missense mutations and were retained. Five of the missense mutations resulted in undetectable levels of SwrB protein by Western blot analysis and were discarded as their defect was likely due to protein instability. The remaining five alleles produced wild type levels of protein (Fig 5A) and were defective in rescuing $\sigma^{\mathrm{D}}$-dependent gene expression to a swrA swrB mutant background (Fig $5 \mathrm{~B}$ ). One mutation was a conservative substitution of a histidine to an arginine (SwrB $\left.{ }^{\mathrm{H} 13 \mathrm{R}}\right)$ within the $\mathrm{N}$ terminal transmembrane helix (Fig 6A, Fig 4C). Three mutations closely clustered the junction between the transmembrane segment and the large C-terminal domain (Fig 6A, Fig 4C), and each of the junction mutations exhibited anomalous protein mobility when resolved by SDS-PAGE (SwrB ${ }^{\mathrm{L} 48 \mathrm{~S}}$, $\mathrm{SwrB}^{\mathrm{F51S}}$, SwrB ${ }^{\mathrm{L53P}}$ ) (Fig 5A). The last mutation was near the C-terminus of the protein (SwrB ${ }^{\mathrm{L155P}}$ ) (Fig 6A, Fig 4C). We conclude that residues throughout SwrB are required for SwrB function.

To determine the consequences of the different alleles of SwrB on localization, the gene encoding YFP was fused to each mutant allele in the complementation construct and introduced to a swrB mutant. One substitution, SwrB ${ }^{\mathrm{H} 13 \mathrm{R}}$, located within the transmembrane domain resulted in seemingly undetectable SwrB-YFP signal (Fig. 6B). SwrB-YFP signal was faint even for the wild type 
209 allele, and since SwrB ${ }^{\mathrm{H} 13 \mathrm{R}}$ makes similar levels of protein (Fig 5A), we suspect that the loss of

$\mathrm{SwrB}^{\mathrm{H} 13 \mathrm{R}}$-YFP signal was due to loss of punctate localization and diffusion of signal throughout the

membrane. We note that histidine residues are uncommon within transmembrane domains. When site-directed mutagenesis was used to change histidine 13 to a membrane-compatible hydrophobic leucine residue (SwrB ${ }^{\mathrm{H} 13 \mathrm{~L}}$-YFP), the resulting construct also abolished punctate localization of SwrB indicating that histidine was required and that the defect was not allele-specific (Fig. 6B). The other four loss-of-function alleles, $\mathrm{SwrB}^{\mathrm{L48S}}, \mathrm{SwrB}^{\mathrm{F51S}}, \mathrm{SwrB}^{\mathrm{L53P}}$, and $\mathrm{SwrB}^{\mathrm{L} 155 \mathrm{P}}$ all retained punctate localization (Fig 6B). We conclude that punctate localization is necessary but not sufficient for SwrB function. We further conclude that punctate localization is mediated by interactions within the transmembrane segment, while the extracellular domain of SwrB may be required for activating the flagellar type III secretion system.

Finally, each of the swrB alleles encoded within the ectopic complementation construct were tested for swarming motility in a background mutated for the native copy of swrB. Three of the alleles in the junction domain, SwrB ${ }^{\mathrm{L} 48 \mathrm{~S}}, \mathrm{SwrB}^{\mathrm{F51S}}$, SwrB ${ }^{\mathrm{L53P}}$ could not complement the null mutation and exhibited a severe defect in swarming (Fig 1C). The $\mathrm{SwrB}^{\mathrm{H} 13 \mathrm{R}}$ allele in the transmembrane domain and the $\mathrm{SwrB}^{\mathrm{L} 155 \mathrm{P}}$ allele near the $\mathrm{C}$-terminus however, restored swarming to the swrB mutant (Fig 1C). We conclude that some of the alleles that were screened for SwrB loss-of-function are instead down-but-not-out allele, as their phenotype was conditional on the simultaneous loss of SwrA. We further conclude that the junction domain of SwrB is the most critical for SwrB activity and confers a loss of function phenotype regardless of genetic background. 


\section{DISCUSSION}

SwrB is a narrowly-distributed protein that is required to increase flagellar number during swarming motility. In the absence of SwrB, flagellar assembly is restricted at an unusual step as there is a dramatic reduction in the number of flagellar hooks despite a wild type number of basal bodies (17). Analysis of suppressor mutations that restored swarming to a swrB mutant suggested the $B$. subtilis flagellar type III secretion system is assembled in an inactive state, and becomes activated when surrounded by the basal body protein FliF, docked with a functional cytoplasmic Cring made of FliG, FliM and FliY $(17,45)$. It was proposed that complete assembly of the supercomplex acted as a checkpoint so that rod subunits would not be secreted until the basal body, upon which they are to be polymerized, is mature. In the context of this model, SwrB was proposed to be a chaperone that accelerated basal body maturation but the mechanism of how SwrB might serve such a role was unclear. Here we further characterize SwrB and reveal constraints on its putative mechanism.

The localization of SwrB informs function. Fluorescent fusions to SwrB were functional and localized as faint puncta at the cell membrane. The low fluorescence intensity of the fusion indicates that SwrB is in low-abundance, and the number of the SwrB puncta were fewer than the number of basal bodies in the cell. Both the low abundance and substoichiometric ratio of SwrB to its putative target support the notion that SwrB acts catalytically to promote basal body assembly. Moreover, puncta of SwrB formed even in the absence of the basal body and rarely co-localized with flagellar hooks. Thus, SwrB either accelerates basal body maturation remotely or, more likely, localizes to basal bodies transiently prior to rod and hook secretion. Remote activity could include the synthesis of a small molecule which somehow potentiates basal body assembly, or the post-translational modification of a key structural component prior to incorporation into the flagellum. Transient association, on the other hand, would be consistent with a protein-folding chaperone. 
SwrB is not homologous to proteins of known function and thus if it is involved in the enzymatic synthesis of a small molecule, or modifies a flagellar structural subunit, it does so using a domain not previously studied. Random mutagenesis was used to determine putative "active site" residues required for SwrB function. A charged residue, histidine ${ }^{13}$, within the transmembrane segment was required for punctate localization, but mutation of that residue acted as a down-but-not-out allele defective only when SwrB levels were low. Thus, puncta formation may be a way to increase local SwrB protein concentration to levels necessary for activity but appears to have reduced importance during conditions that promote swarming motility when SwrB levels rise. Three hydrophobic residues leucine ${ }^{48}$, phenylalanine ${ }^{51}$, and leucine ${ }^{53}$ distal to the transmembrane segment, when mutated, conferred severe functional defects under all conditions tested and substitution of the critical residues resulted in anomalous protein mobility in SDS-PAGE. Anomalous migration has been attributed to differential access of detergent, perhaps by constrained secondary or tertiary folding (67-70), suggesting that domain flexibility and dynamism may be critical for SwrB function. Finally, the three critical residues, and another conditionally-required residue leucine ${ }^{155}$, flank a region of low sequence conservation (Fig 6A). The region of low conservation seems inconsistent with a sequenceconstrained enzymatic domain, but could be an interaction surface that specifies the SwrB target.

Whether SwrB directly interacts with the flagellar basal body and/or any of the flagellar structural subunits is unknown. The range of potential targets for interaction however is constrained by SwrB topology. SwrB is a single-pass transmembrane protein with an $\mathrm{N}$-terminal transmembrane helix consistent with a Sec-dependent secretion signal. Normally, Sec-secretion signals are inserted such that the $\mathrm{N}$-terminus is oriented towards the cytoplasm guided by positively charged amino acids proximal to the helix according to the "positive inside rule" $(50,71)$. SwrB, however, has positively charged amino acids distal to the helix predicting an atypical topology in which the $\mathrm{N}$-terminus was extracellular. Here we use translational fusions of $\beta$-galactosidase and alkaline phosphatase to support the topology prediction and demonstrate that SwrB is oriented such that the majority of its 
mass is cytoplasmic. Thus, if SwrB interacts with a flagellar component, we predict it would be a component largely contained within the cytoplasm as well. One candidate target could be the FliFFliG rotor surface as mutations that stabilized FliG assembly suppressed the absence of SwrB. Other suppressors of swrB overexpressed the secretion protein FliP and thus SwrB could interact with the cytoplasmic domains of one or more flagellar type III secretion proteins.

With respect to type III secretion, it was brought to our attention that a distant relative of SwrB in Campylobacter jejuni called FlgW, interacts with a protein called FliO (personal communication, Beile Gao; 72). FliO is found in flagellar type III secretion systems but not in paralogous injectisomes, and recent work indicates that FliO is a regulator of the flagellar type III protein FliP (73-75). In $B$. subtilis, FliO is predicted to contain two transmembrane segments, and like SwrB, FliO is predicted to have a large C-terminal domain in the cytoplasm. If SwrB were to bind to and regulate FliO, it could explain the increased frequency of flagellar type III secretion activation as well as the observation that excess FliP could bypass the absence of SwrB, perhaps by FliO titration. To be clear, FliO as a target of SwrB is entirely speculative and nearly all research on FliO activity has been performed in Salmonella enterica, an organism lacking a SwrB homolog. We note however the uncanny similarities in localization, topology, and function between SwrB and Flk, a poorly understood singlepass transmembrane protein that regulates the $S$. enterica flagellar type III secretion system (76-79). Thus, we wonder whether the coupling of flagellar basal body maturation to secretion activation is conserved even if the proteins that regulate the checkpoint are not. 


\section{MATERIALS AND METHODS:}

Strains and growth conditions. B. subtilis strains were grown in lysogeny broth (LB) $(10 \mathrm{~g}$ tryptone, $5 \mathrm{~g}$ yeast extract, $5 \mathrm{~g} \mathrm{NaCl}$ per L) broth or on LB plates fortified with $1.5 \%$ Bacto agar at $37^{\circ} \mathrm{C}$. When appropriate, antibiotics were included at the following concentrations: $10 \mu \mathrm{g} / \mathrm{ml}$ tetracycline, $100 \mu \mathrm{g} / \mathrm{ml}$ spectinomycin, $5 \mu \mathrm{g} / \mathrm{ml}$ chloramphenicol, $5 \mu \mathrm{g} / \mathrm{ml}$ kanamycin, and $1 \mu \mathrm{g} / \mathrm{ml}$ erythromycin plus $25 \mu \mathrm{g} / \mathrm{ml}$ lincomycin $(\mathrm{m} / \mathrm{s})$. For the swarm expansion assay, swarm agar plates containing $25 \mathrm{ml} \mathrm{LB}$ fortified with $0.7 \%$ Bacto agar were prepared fresh and the following day were dried for a total of 20 minutes in a laminar flow hood (see below).

Strain construction. All constructs were first introduced into the domesticated strain PY79 or the cured strain DS2569 by natural competence and then transferred to the 3610 background using SPP1-mediated generalized phage transduction (80-81). All strains used in this study are listed in Table 1. All primers used in this study are listed in Supplemental Table S1. All plasmids used in this study are listed in Supplemental Table S2.

Fluorescent fusions. To generate the $\mathrm{P}_{\text {flache-swrB-linker-yfp translational fusion construct }}$ (pAP36), a PCR product containing linker-yfp was amplified from B. subtilis DS5436 chromosomal DNA using the primer pair 2634/2635 and digested with Sall and BamHI. The fragment was then ligated into the Sall and BamHI sites of pAH25 containing a spectinomycin resistance cassette between two arms of the amyE gene (generous gift by Amy Camp, Mount Holyoke College) to generate pAP35. Next, a PCR product containing $P_{\text {flache }}-s w r B$ was amplified from B. subtilis DS6350 chromosomal DNA using the primer pair 2636/2637 and digested with EcoRI and Sall. The fragment was then ligated into the EcoRI and Sall sites of pAP35 to generate pAP36.

To generate the mutated $P_{\text {flache-swrB-linker-yfp translational fusions were amplified using }}$ primer pair 2636/2637 and chromosomal DNA from the following strains: DS7749 (swrB ${ }^{F 51 S}$ ), DS7513 $\left(s w r B^{H 13 R}\right), D S 7750\left(s w r B^{L 155 P}\right), D S 7244\left(s w r B^{L 53 P}\right)$, and DS7748 (swrB $\left.{ }^{L 48 S}\right)$. Each fragment was 
purified, digested with EcoRI and Sall and ligated into the EcoRI/Sall sites of pAP35 to generate pAP37, pAP40, pAP41 pAP42, and pAP43 respectively.

To generate swrB $\Omega$ GFP spec, a fragment containing $s w r B$ was amplified from $B$. subtilis 3610 chromosomal DNA using the primer pair 384/385 and digested with EcoRI and Xhol, and the fragment containing gfp was amplified from pMF35 using the primer pair 995/996 and digested with Xhol and HindIII (82). The two fragments were then simultaneously ligated into the EcoRI and HindIII sites of pUS19 to generate pDG136 (83).

PhoA fusion topology reporters. To generate a phoA topology reporter system for $B$. subtilis, the phoA gene from Escherichia coli was codon optimized for $B$. subtilis by gene synthesis (Integrated DNA technologies) with a 5' fusion of the motB gene from B. subtilis. The synthesized gene fragment was then used as a template and PCR amplified with primer pair 7476/7478 and 7477/7478, digested with Sall/Sphl and cloned into the Sall/Sphl sites of pDR111 containing the $P_{\text {hyspank }}$ promoter, a polylinker, the lacl gene, and a gene encoding for spectinomycin resistance between the arms of the amyE gene for ectopic integration (generous gift of David Rudner, Harvard Medical School), to generate plasmids pDP545 (amyE::Physpank-motB'phoA) and pDP546 (amyE:: $P_{\text {hyspank }}-n o^{T M}$ phoA), respectively. The plasmid pDP545 was constructed such that the 5' end of theoretically any gene could be cloned between the Sall site and an internal Nhel site immediately upstream of the phoA coding region to generate in-frame translational fusions to phoA. As such, extended fragments of the $5^{\prime}$ ends of the motB and swrB genes were PCR amplified using pDP545 and DK1042 chromosomal DNA as a template respectively and and primer pairs 7476/7507 and $7489 / 7490$ respectively. Each product was purified, digested with Sall and Nhel, and cloned into the

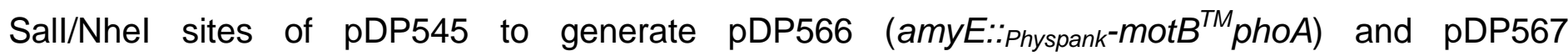
(amyE::P $P_{\text {hyspank }}-S w r B^{T M}$ phoA) respectively

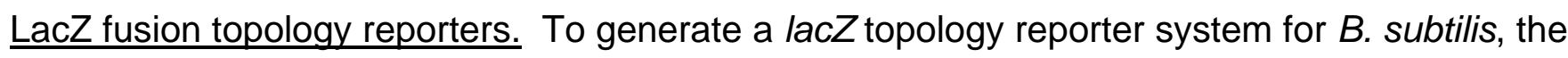
lacZ gene from Escherichia coli was codon optimized for $B$. subtilis by gene synthesis (Blue Heron 
351

352

353

354

355

356

357

358

359

360

361

362

363

364

365

366

367

368

369

370

371

372

373

374

Gene Synthesis) and cloned into the HindlII/Sphl sites of pDR111 to create pDP559 (amyE:: $P_{\text {hyspank- }}{ }^{-}$ no ${ }^{T M}$ lacZ). The plasmid pDP559 was constructed such that the exact same fragment cloned upstream of phoA in pDP545 could also be cloned into immediately upstream of the lac $Z$ coding region. As such, extended fragments of the 5' ends of the motB and swrB genes were PCR amplified using pDP545 and 3610 chromosomal DNA as a template respectively and primer pairs 7476/7507 and 7489/7490 respectively. Each product was purified, digested with Sall and Nhel, and cloned into the Sall/Nhel sites of pDP559 to generate pDP568 (amyE::Physpank-motB ${ }^{T M}$ lacZ) and pDP569 (amyE:: $P_{\text {hyspank }}-S w r B^{T M} l a c Z$ ) respectively.

phoA::m/s. To generate the phoA::m/s marker replacement insertion/deletion allele, the region upstream of phoA was PCR amplified using primers $7382 / 7383$ and the region downstream of phoA was PCR amplified using primers 7384/7385 using chromosomal DNA from DK1042 as a template. Next the erm cassette (conferring resistance to erythromycin and lincomycin, $m / s$ ) was amplified using primers 3250/3251 using pAH52 (generous gift from Amy Camp, Mount Hoyloke College) as a template. The three PCR products were purified, mixed in equal ratios in an isothermal assembly reaction. The reaction was then transformed into PY79 selecting for $\mathrm{m} / \mathrm{s}$ resistance.

phoB::tet. The phoB::tet allele was acquired from Patrick Eichenberger, New York University (84).

Allelic replacement. The $s w r B^{H 13 L}$ allele was generated using isothermal "Gibson" assembly (ITA) (85). A fragment containing the $5^{\prime}$ half of $s w r B$, the spectinomycin-resistance marker (spec), and the 5' amyE arm approximately 3000 bp upstream of the swrB gene was PCR amplified from DS8161 using primer pair 3177/3292, and a fragment containing the $3^{\prime}$ half of $s w r B$, a polylinker, and the 3' amyE arm approximately 3000 bp downstream of the swrB gene was PCR amplified using primer pair 3291/3180. Primers 3292 and 3291 are reverse complements and were used to change codon 13 of swrB from CAC (histidine) to CTT (leucine). 
Isothermal assembly reaction buffer (5x) $(500 \mathrm{mM}$ Tris- $\mathrm{HCl}[\mathrm{pH} 7.5], 50 \mathrm{mM} \mathrm{MgCl}, 50 \mathrm{mM}$ dithiothreitol [DTT] [Bio-Rad], 31.25 mM polyethylene glycol 8000 [PEG 8000] [Fisher Scientific], 5.02 mM NAD [Sigma-Aldrich], and $1 \mathrm{mM}$ each deoxynucleoside triphosphate [dNTP] [New England BioLabs]) was aliquoted and stored at $-80^{\circ} \mathrm{C}$. An assembly master mixture was made by combining prepared $5 \times$ isothermal assembly reaction buffer $(131 \mathrm{mM}$ Tris- $\mathrm{HCl}, 13.1 \mathrm{mM} \mathrm{MgCl}, 13.1 \mathrm{mM} \mathrm{DTT}$, 8.21 mM PEG 8000, 1.32 mM NAD, and 0.26 mM each dNTP) with Phusion DNA polymerase (New England BioLabs) (0.033 units/ $\mu \mathrm{l})$, T5 exonuclease diluted 1:5 with $5 \times$ reaction buffer (New England BioLabs) (0.01 units/ $\mu \mathrm{l})$, Taq DNA ligase (New England BioLabs) (5,328 units/ $\mu \mathrm{l})$, and additional dNTPs $(267 \mu \mathrm{M})$. The master mix was aliquoted as $15 \mu \mathrm{l}$ and stored at $-80^{\circ} \mathrm{C}$.

The two DNA fragments were combined at equimolar amounts to a total volume of $5 \mu$ and added to a $15-\mu l$ aliquot of prepared master mix. The reaction mixture was incubated for $60 \mathrm{~min}$ at $50^{\circ} \mathrm{C}$. The completed reaction generated a $6 \mathrm{~kb}$ DNA fragment that was PCR amplified using the primer pair 3177/3180, and then directly transformed into PY79. Chromosomal DNA was purified from colonies resistant for spectinomycin and PCR amplified using primer pair 2636/2635 to determine which isolate had retained the $s w r B^{H 13 L}$ allele.

PCR mutagenesis. To generate a pool of swrB mutants, primer pair 861/862 was used to amplify the amyE construct containing $s w r B$ open reading frame under the control of the $\mathrm{P}_{\text {flache }}$ promoter $\left(P_{\text {flache }}\right.$-swrB cat). DS6350 chromosomal DNA was used as a template and Expand polymerase with Expand Buffer 2 (Roche). The resulting PCR fragment was purified using the QIAquick PCR purification kit (Qiagen) and transformed into PY79. All of the resulting colonies were pooled together and used to generate a lysate library of $s w r B^{\text {mut }}$ complementation constructs. The lysate library was SPP1 subsequently transformed into DS6334, and the resulting transductants were patched onto LB containing X-Gal to screen for swrB mutants that fail to complement.

Direct Sanger Sequencing. For swrB point mutations generated through PCR mutagenesis, a PCR product containing the swrB open reading frame was amplified from $B$. subtilis chromosomal 
DNA (either from strain 3610 or the appropriate mutant strain) using the primer set $2429 / 2430$. The swrB PCR product was then sequenced using primer 2429 and 2430 individually.

SPP1 phage transduction. To $0.2 \mathrm{ml}$ of dense culture grown in TY broth (LB broth supplemented after autoclaving with $10 \mathrm{mM} \mathrm{MgSO}_{4}$ and $100 \mu \mathrm{M} \mathrm{MnSO}_{4}$ ), serial dilutions of SPP1 phage stock were added and statically incubated for 15 minutes at $37^{\circ} \mathrm{C}$. To each mixture, $3 \mathrm{ml}$ TYSA (molten TY supplemented with $0.5 \%$ agar) was added, poured atop fresh TY plates, and incubated at $30^{\circ} \mathrm{C}$ overnight. Top agar from the plate containing near confluent plaques was harvested by scraping into a $15 \mathrm{ml}$ conical tube, vortexed, and centrifuged at $5,000 \times \mathrm{g}$ for 5 minutes. The supernatant was treated with $25 \mu \mathrm{g} / \mathrm{ml}$ DNase final concentration before being passed through a $0.45 \mu \mathrm{m}$ syringe filter and stored at $4^{\circ} \mathrm{C}$.

Recipient cells were grown to stationary phase in $3 \mathrm{ml} \mathrm{TY}$ broth at $37^{\circ} \mathrm{C} .1 \mathrm{ml}$ cells were mixed with $25 \mu \mathrm{l}$ of SPP1 donor phage stock. $9 \mathrm{ml}$ of TY broth was added to the mixture and allowed to stand at $37^{\circ} \mathrm{C}$ for 30 minutes. The transduction mixture was then centrifuged at $5,000 \times \mathrm{g}$ for 5 minutes, the supernatant was discarded and the pellet was resuspended in the remaining volume. $100 \mu \mathrm{l}$ of cell suspension was then plated on LB fortified with $1.5 \%$ agar, the appropriate antibiotic, and $10 \mathrm{mM}$ sodium citrate.

Swarm expansion assay. Cells were grown to mid-log phase at $37^{\circ} \mathrm{C}$ in LB broth and resuspended to $10 \mathrm{OD}_{600}$ in $\mathrm{pH} 8.0$ PBS buffer $\left(137 \mathrm{mM} \mathrm{NaCl}, 2.7 \mathrm{mM} \mathrm{KCl}, 10 \mathrm{mM} \mathrm{Na}_{2} \mathrm{HPO}_{4}\right.$, and 2 $\mathrm{mM} \mathrm{KH}_{2} \mathrm{PO}_{4}$ ) containing $0.5 \%$ India ink (Higgins). Freshly prepared LB containing $0.7 \%$ Bacto agar $(25 \mathrm{ml} /$ plate) was dried for 10 minutes in a laminar flow hood, centrally inoculated with $10 \mu \mathrm{l}$ of the cell suspension, dried for another 10 minutes, and incubated at $37^{\circ} \mathrm{C}$. The India ink demarks the origin of the colony and the swarm radius was measured relative to the origin. For consistency, an axis was drawn on the back of the plate and swarm radii measurements were taken along this transect. For experiments including IPTG, cells were propagated in broth in the presence of IPTG, and IPTG was included in the swarm agar plates. 
Plate-based PhoA and LacZ assays. Stocks 5-bromo-4-chloro-3-indolyl- $\beta$-Dgalactopyranoside (X-Gal, Sigma-Aldritch) and 5-bromo-4-chloro-3-indolyl-phosphate disodium salt (X-P, Sigma-Aldritch) were made immediately before use by dissolving $20 \mathrm{mg}$ of either compound in $1 \mathrm{ml}$ dimethylformamide (DMF) or $1 \mathrm{ml}$ deionized water, respectively. The X-P solution was filter sterilized and both solutions were stored in opaque Eppendorf tubes. $100 \mathrm{ul}$ of each solution was spread atop separate LB plates fortified with 1.5\% agar containing $1 \mathrm{mM} \mathrm{IPTG}$ and the solutions were allowed to absorb into the agar for $1 \mathrm{hr}$ at $37^{\circ} \mathrm{C}$ in the dark. Cells were then struck on the plates and incubated at $30^{\circ} \mathrm{C}$ overnight. The back slides of the Petri plates were photographed using a Kodak Pixpro FZ53 digital camera.

Western blotting. B. subtilis strains were grown in $\mathrm{LB}$ broth to $\mathrm{OD}_{600} \sim 0.5,1 \mathrm{ml}$ was harvested by centrifugation, and resuspended to $10 \mathrm{OD}_{600}$ in Lysis buffer $(20 \mathrm{mM}$ Tris $\mathrm{pH}$ 7.0, $10 \mathrm{mM}$ EDTA, $1 \mathrm{mg} / \mathrm{ml}$ lysozyme, $10 \mu \mathrm{g} / \mathrm{ml}$ DNAse I, $100 \mu \mathrm{g} / \mathrm{ml}$ RNAse I, $1 \mathrm{mM}$ PMSF) and incubated 30 minutes at $37^{\circ} \mathrm{C}$. Each lysate was then mixed with the appropriate amount of $6 x$ SDS loading dye to dilute the loading dye to $1 x$ concentration. Samples were separated by $12 \%$ Sodium dodecyl sulfatepolyacrylamide gel electrophoresis (SDS-PAGE). The proteins were electroblotted onto nitrocellulose and developed with a 1:10,000 dilution of (anti-SwrB), 1:10,000 dilution of (anti-GFP), or 1:80,000 dilution of (anti-SigA) of primary antibody and a 1:10,000 dilution secondary antibody (horseradish peroxidase-conjugated goat anti-rabbit immunoglobulin G). Immunoblot was developed using the Immun-Star HRP developer kit (Bio-Rad).

Microscopy. Fluorescence microscopy was performed with a Nikon 80i microscope along with a phase contrast objective Nikon Plan Apo 100X and an Excite 120 metal halide lamp. Alexa Fluor $594 \mathrm{C}_{5}$ maleimide fluorescent signals were visualized with a C-FL HYQ Texas Red Filter Cube (excitation filter $532-587 \mathrm{~nm}$, barrier filter $>590 \mathrm{~nm}$ ). GFP was visualized using a C-FL HYQ FITC Filter Cube (FITC, excitation filter 460-500 nm, barrier filter 515-550 nm). YFP was visualized using a C_FL HYQ YFP Filter Cube (excitation filter 490-510 nm, barrier filter 515-550 nm). TMA-DPH 
450 fluorescent signal was visualized using a UB-2E/C DAPI Filter Cube (excitation filter 340-380 nm,

barrier filter $435-485 \mathrm{~nm}$ ). Images were captured with a Photometrics Coolsnap $\mathrm{HQ}^{2}$ camera in black and white, false colored and superimposed using Metamorph image software.

For $P_{\text {flache }}$-SwrB-YFP microscopy, cells were grown at $37^{\circ} \mathrm{C}$ in LB broth to $\mathrm{OD}_{600}$ 0.6-1.0, resuspended in $30 \mu \mathrm{l}$ PBS buffer containing $0.1 \mathrm{mM}$ TMA-DPH and incubated for $5 \mathrm{~min}$ at room temperature. The cells were pelleted, resuspended in $30 \mu \mathrm{l}$ PBS buffer, and were observed by spotting $4 \mu \mathrm{l}$ of suspension on a cleaned microscope slide and immobilized with a poly-L-lysinetreated glass coverslip.

For fluorescent microscopy of swrB $\Omega$ GFP and flagellar hooks, $1.0 \mathrm{ml}$ of broth culture was harvested at $0.6-1.0 \mathrm{OD}_{600}$, resuspended in $50 \mu$ of PBS buffer containing $5 \mu \mathrm{g} / \mathrm{ml}$ Alexa Fluor $594 \mathrm{C}_{5}$ maleimide (Molecular Probes), incubated for $3 \mathrm{~min}$ at room temperature, and washed once in $1.0 \mathrm{ml}$ of PBS buffer. The suspension was pelleted, resuspended in $30 \mu$ of PBS buffer containing $0.1 \mathrm{mM}$ TMA-DPH, and incubated for $5 \mathrm{~min}$ at room temperature. The cells were pelleted, resuspended in 30 $\mu$ I PBS buffer, and were observed by spotting $4 \mu$ of suspension on a cleaned microscope slide and immobilized with a poly-L-lysine-treated glass coverslip.

$\beta$-Galactosidase assays. Cells were harvested from cultures growing at $37^{\circ} \mathrm{C}$ in LB broth. Cells were collected in $1.0 \mathrm{ml}$ aliquots and suspended in an equal volume of $Z$ buffer $(40 \mathrm{mM}$ $\mathrm{NaH}_{2} \mathrm{PO}_{4}, 60 \mathrm{mM} \mathrm{NaHPO}, 1.0 \mathrm{mM} \mathrm{MgSO}_{4}, 10 \mathrm{mM} \mathrm{KCl}$, and $38 \mathrm{mM}$ 2-mercaptoethanol). Lysozyme was added to each sample to a final concentration of $0.2 \mathrm{mg} / \mathrm{ml}$ and incubated at $37^{\circ} \mathrm{C}$ for 30 min. Each sample was diluted in $Z$ buffer to a final volume of $500 \mu \mathrm{l}$, and the reaction was started with 100 $\mu \mathrm{l}$ of $4 \mathrm{mg} / \mathrm{ml}$ 2-nitrophenyl $\beta$-galactopyranoside (ONPG, Sigma-Aldritch) in Z buffer and stopped with $250 \mu \mathrm{l}$ of $1 \mathrm{M} \mathrm{Na}_{2} \mathrm{CO}_{3}$. The $\mathrm{OD}_{420}$ of the reaction mixture was measured, and the $\beta$-galactosidasespecific activity was calculated according the equation $\left[\mathrm{OD}_{420} /\left(\right.\right.$ time $\left.\left.\mathrm{X} \mathrm{OD}_{600}\right)\right] \mathrm{X}$ dilution factor $\mathrm{X} 1000$. 
475 We are grateful to Cristina Landeta for guidance in the development of the alkaline phosphatase

476 reporter system. Special thanks go to Kearns lab members for their intellectual support; Loralyn

477 Cozy, Joyce Patrick, Rebecca Calvo, Melissa Konkol, Eric Vanderpool, Anna Bree, Sampriti 478 Mukherjee, and others. This work was funded by USDA grant WIS02030 to BMB and National 479 Institutes of Health R35 grant GM131783 to DBK. 
Table 1: Strains ${ }^{a}$

\begin{tabular}{|c|c|}
\hline Strain & Genotype \\
\hline 3610 & Wild type \\
\hline PY79 & $\operatorname{sfp}^{0}$ swrA ${ }^{F S}$ epsC \\
\hline DK201 & $\Delta s w r B$ amyE::P $P_{\text {flache }}$-swrB ${ }^{H 13 L}$-linker-yfp spec \\
\hline DK204 & $\Delta$ fliF swrB::tet amyE::P $P_{\text {flache-swrB-linker-yfp spec }}$ \\
\hline DK235 & $\triangle$ fliP swrB::tet amyE::P flache-swrB-linker-yfp spec \\
\hline DK310 & $\Delta f l h A$ swrB::tet amyE::P $P_{\text {flache-SwrB-linker-yfp spec }}$ \\
\hline DK3843 & [PY79] phoA::m/s phoB::tet \\
\hline DK8730 & 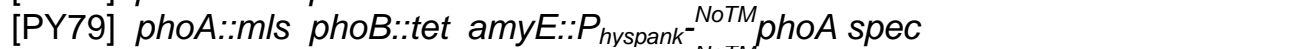 \\
\hline DK9023 & 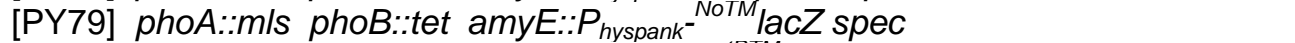 \\
\hline DK9039 & [PY79] phoA::mls phoB::tet amyE:: $P_{\text {hyspank }}^{-{ }^{\text {motBIM }}}$ phoA spec \\
\hline DK9040 & [PY79] phoA::m/s phoB::tet amyE:: $P_{\text {hyspank }}{ }^{-}{ }^{\text {wrBIM }}$ phoA spec \\
\hline DK9041 & 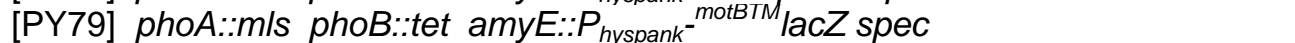 \\
\hline DK9042 & [PY79] phoA::m/s phoB::tet amyE:: $P_{\text {hyspank }}{ }^{\text {sw }}$ \\
\hline DS2509 & (Patrick and Kearns, 2009) \\
\hline DS2522 & $\Delta s w r B$ amyE ::P $P_{\text {flache }}-s w r B$ cat \\
\hline DS6332 & swrA::kan thrC:: $P_{\text {hag }}-1 a c Z \mathrm{~m} / \mathrm{s}$ \\
\hline DS6334 & swrA::kan swrB::tet thrC:: $P_{h a g}-l a c Z \mathrm{~m} / \mathrm{s}$ \\
\hline DS6350 & swrA::kan swrB::tet thrC:: $P_{h a g}-l a c Z \mathrm{mls}$ amyE::P $P_{\text {flache}}-\mathrm{swrB}$ cat \\
\hline DS7244 & 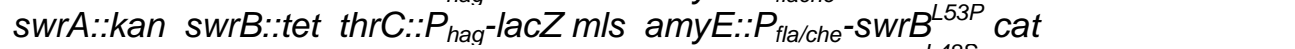 \\
\hline DS7443 & swrA::kan swrB::tet thrC::P $P_{\text {haq }}$-lacZ m/s amyE:: $P_{\text {flache }}-s w r B^{L 48 S}$ cat \\
\hline DS7513 & swrA::kan swrB::tet thrC:: $P_{\text {hag }}-l a c Z$ mls amyE:::Pfla/che-swrB ${ }^{H 13 R}$ cat \\
\hline DS7606 & $\Delta s w r B$ amyE $:: P_{\text {flache }}-S w r B^{H 13 R}$ cat \\
\hline DS7669 & $\Delta s w r B$ amyE $:: P_{\text {flache }}-s w r B^{L 53 P}$ cat \\
\hline DS7749 & swrA::kan swrB::tet thrC:: $P_{h a g}-l a c Z$ mls amyE::: $P_{\text {fla/che }}-s w r B^{F 51 s}$ cat \\
\hline DS7750 & swrA::kan swrB::tet thrC:: $P_{h a q}-l a c Z \mathrm{mls}$ amyE $:: P_{\text {fla/che}}-s w r B^{L 155 P}$ cat \\
\hline DS7781 & $\Delta s w r B$ amyE:: $P_{\text {flache }}-s w r B^{L 48 S}$ cat \\
\hline DS7782 & $\Delta s w r B$ amyE $:: P_{\text {flache }}-s w r B^{F 51 S}$ cat \\
\hline DS7783 & $\Delta s w r B$ amyE:: $P_{\text {flache }}-S w r B^{L 155 P}$ cat \\
\hline DS8161 & $\Delta s w r B$ amyE::P $P_{\text {flache }}$-swrB-linker-yfp spec \\
\hline DS8348 & $\Delta s w r B$ amyE $:: P_{f l a / c h e}-s w r B^{F 51 S}$-linker-yfp spec \\
\hline DS8364 & $\Delta s w r B$ amyE $:: P_{\text {fla/che }}-s w r B^{H 13 R}$-linker-yfp spec \\
\hline DS8483 & $\Delta s w r B$ amyE:: $P_{\text {fla/che }}-s w r B^{L 155 P}$-linker-yfp spec \\
\hline DS8484 & $\Delta s w r B$ amyE:: $P_{\text {fla/che }}-s w r B^{L 53 P}$-linker-yfp spec \\
\hline DS8485 & $\Delta s w r B$ amyE:: $P_{f l a / c h e}-s w r B^{L 48 P}$-linker-yfp spec \\
\hline DS9404 & $\triangle f l g E$ amyE:: $P_{f l a / c h e} e^{-f l g} E^{T 123 C}$ cat swrB $\Omega g f p$ spec \\
\hline
\end{tabular}

${ }^{a}$ All strains are in the undomesticated 3610 genetic background unless otherwise indicated. 


\section{REFERENCES}

1. Kearns DB, Losick R. 2003. Swarming motility in undomesticated Bacillus subtilis. Mol Microbiol 49:581-590.

2. Kearns DB, Chu F, Rudner R, Losick R. 2004. Genes governing swarming in Bacillus subtilis and evidence for a phase variation mechanism controlling surface motility. Mol Microbiol 52:357-69.

3. Julkowska D, Obuchowski M, Holland IB, Séror SJ. 2004. Comparative analysis of the development of swarming communities of Bacillus subtilis 168 and a natural wild type: critical effects of surfactin and the composition of the medium. J Bacteriol 187:65-76.

4. Wu Y, Berg HC. 2012. Water reservoir maintained by cell growth fuels the spreading of a bacterial swarm. Proc Natl Acad Sci USA 109:4128-4133.

5. Ke WJ, Hsueh YH, Cheng YC, Wu CC, Liu ST. 2015. Water surface tension modulates the swarming mechanics of Bacillus subtilis. Front Microbiol 6:1017.

6. Hall AN, Subramanian S, Oshiro RT, Canzoneri AK, Kearns DB. 2018. SwrD (Ylzl) promotes swarming in Bacillus subtilis by increasing power to flagellar motors. J Bacteriol 200:e00529-17.

7. Senesi S, Ghelardi E, Celandroni F, Salvetti S, Parisio E, Galizzi A. 2004. Surface-associated flagellum formation and swarming differentiation in Bacillus subtilis are controlled by the ifm locus. J Bacteriol 186:1158-1164.

8. Kearns DB, Losick R. 2005. Cell population heterogeneity during growth of Bacillus subtilis. Genes Dev 19:3083-3094.

9. Guttenplan SB, Shaw S, Kearns DB. 2013. The cell biology of peritrichous flagella in Bacillus subtilis. Mol Microbiol 87:211-229.

10. Mukherjee S, Bree AC, Liu J, Patrick JE, Chien P, Kearns DB. 2015. Adaptor-mediated Lon proteolysis restricts Bacillus subtilis hyperflagellation. Proc Natl Acad Sci USA 112:250-255.

11. Calvio C, Celandroni F, Ghelardi E, Amati G, Salvetti S, Ceciliani F, Galizzi A, Senesi S. 2005. Swarming differentiation and swimming motility in Bacillus subtilis are controlled by $s w r A$, a newly identified dicistron. J Bacteriol 187:5356-5366.

12. Calvio C, Osera C, Amati G, Galizzi A. 2008. Autoregulation of swrAA and motility in Bacillus subtilis. J Bacteriol 190:5720-5728.

13. Tsukuhara K, Ogura M. 2008. Promoter selectivity of the Bacillus subtilis response regulator $\mathrm{DegU}$, a positive regulator of the fla/che operon and sacB. BMC Microbiol 8:8.

14. Ogura M, Tsukuhara K. 2012. SwrA regulates assembly of Bacillus subtilis DegU via its interaction with N-terminal domain of DegU. J Biochem 151:645-655. 
15. Mordini S, Osera C, Marini S, Scavone F, Bellazzi R, Galizzi A, Calvio C. 2013. The role of SwrA, DegU, and P(D3) in fla/che expression in B. subtilis. PLoS One 8:e85065.

16. Werhane H, Lopez P, Mendel M, Zimmer M, Ordal GW, Márquez-Magaña LM. 2004. The last gene of the fla/che operon in Bacillus subtilis, $y / x L$, is required for maximal sigma ${ }^{\mathrm{D}}$ function. $J$ Bacteriol. 186:4025-40299.

17. Phillips AM, Calvo RA, Kearns DB. 2015. Functional activation of the flagellar type III secretion export apparatus. PLoS Genet 11:e1005443.

18. Ueno T, Oosawa K, Aizawa S-I. 1992. M ring, S ring and proximal rod of the flagellar basal body of Salmonella typhimurium are composed of subunits of a single protein, FliF. J Mol Biol 227:672-677.

19. Fan F, Ohnishi K, Francis NR, Macnab RM. 1997. The FliP and FliR proteins of Salmonella typhimurium, putative components of the type III flagellar export apparatus, are located in the basal body. Mol Microbiol 26:1035-1046.

20. Li H, Sourjik V. 2011. Assembly and stability of flagellar motor in Escherichia coli. Mol Microbiol 80:886-899.

21. Lloyd SA, Blair DF. 1997. Charged residues of the rotor protein FliG essential for torque generation in the flagellar motor of Escherichia coli. J Mol Biol 266:733-744.

22. Paul K, Brunstetter D, Titen S, Blair DF. 2011. A molecular mechanism of direction switching in the flagellar motor of Escherichia coli. Proc Natl Acad Sci USA 108:17171-17176.

23. Chang Y, Moon KH, Zhao X, Norris SJ, Motaleb MA, Liu J. 2019. Structural insights into flagellar stator-rotor interactions. eLife 8:e48979.

24. Minamino T, Macnab RM. 1999. Components of the Salmonella flagellar export apparatus and classification of export substrates. J Bacteriol 181:1388-1394.

25. Hirano T, Minamino T, Namba K, Macnab RM. 2003. Substrate specificity classes and the recognition signal for Salmonella type III flagellar export. J Bacteriol 185:2485-2492.

26. Burrage AM, Vanderpool E, Kearns DB. 2018. Assembly order of flagellar rod subunits in Bacillus subtilis. J Bacteriol 200:e00425-18.

27. Hirano T, Yamaguchi S, Oosawa K, Aizawa S-I. 1994. Roles of FliK and FlhB in determination of flagellar hook length in Salmonella typhimurium. J Bacteriol 176:5439-5449.

28. Williams AW, Yamaguchi S, Togashi F, Aizawa S-I, Kawagishi I, Macnab RM. 1996. Mutations in fliK and $f / h B$ affecting flagellar hook and filament assembly in Salmonella typhimurium. J Bacteriol 178:2960-2970.

29. Journet L, Agrain C, Broz P, Cornelis GR. 2003. The needle length of bacterial injectisomes is determined by a molecular ruler. Science 302:1757-1760. 
30. Minamino T, Saijo-Hamano Y, Furukawa Y, González-Pedrajo B, Macnab RM, Namba K. 2004. Domain organization and function of Salmonella FliK, a flagellar hook-length control protein. J Mol Biol 341:491-502.

31. Ferris HU, Furukawa Y, Minamino T, Kroetz MB, Kihara M, Namba K, Macnab RM. 2005. FlhB regulates ordered export of flagellar components via autocleavage mechanism. J Biol Chem 280:41236-41242.

32. Erhardt M, Singer HM, Wee DH, Keener JP, Hughes KT. 2011. An infrequent molecular ruler controls flagellar hook length in Salmonella enterica. EMBO J 30:2948-2961.

33. Zuberi AR, Ying C, Weinreich MR, Ordal GW. 1990. Transcriptional organization of a cloned chemotaxis locus of Bacillus subtilis. J Bacteriol 172:1870-1876.

34. Albertini AM, Caramori T, Crabb WD, Scoffone F, Galizzi A. 1991. The flaA locus of Bacillus subtilis is part of a large operon coding for flagellar structures, motility functions and an ATPase-like polypeptide. J Bacteriol 173:3573-3579.

35. Márquez-Magaña LM, Chamberlin MJ. 1994. Characterization of the sigD transcription unit of Bacillus subtilis. J Bacteriol 176:2427-2434.

36. Mukherjee S, Kearns DB. 2014. The structure and regulation of flagella in Bacillus subtilis. Annu Rev Genet 48:319-340.

37. Helmann JD, Marquez LM, Chamberlin MJ. 1988. Cloning, sequencing, and disruption of the Bacillus subtilis $\sigma^{28}$ gene. J Bacteriol 170:1568-1574.

38. Márquez LM, Helmann JD, Ferrari E, Parker HM, Ordal GW, Chamberlin MJ. 1990. Studies of $\sigma^{\mathrm{D}}$-dependent functions in Bacillus subtilis. J Bacteriol 172:3435-3443.

39. Serizawa M, Yamamoto H, Yamaguchi H, Fujita Y, Kobayashi K, Ogasawara N, Sekiguchi J. 2004. Systematic analysis of SigD-regulated genes in Bacillus subtilis by DNA microarray and Northern blotting analyses. Gene 329:125-136.

40. Kuhlen L, Abrusci P, Johnson S, Gault J, Deme J, Caesar J, Dietsche T, Mebrhatu MT, Ganief T, Macek B, Wagner S, Robinson CV, Lea SM. 2018. Structure of the core of the type III secretion system export apparatus. Nat Struct Mol Biol 25:583-590.

41. Ward E, Renault TT, Kim EA, Erhardt M, Hughes KT, Blair DF. 2018. Type-III secretion pore formed by flagellar protein FliP. Mol Microbiol 107:94-103.

42. Barillà D, Caramori T, Galizzi A. 1994. Coupling of flagellin gene transcription to flagellar assembly in Bacillus subtilis. J Bacteriol 176:4558-4564.

43. Caramori T, Barillà D, Nessi C, Sacchi L, Galizzi A. 1996. Role of FlgM in $\sigma^{\mathrm{D}}$-dependent gene expression in Bacillus subtilis. J Bacteriol 178:3113-3118.

44. Bertero MG, Gonzales B, Tarricone C, Cecliani F, Galizzi A. 1999. Overproduction and characterization of the Bacillus subtilis anti-sigma factor FlgM. J Biol Chem 274:12103-12107. 
45. Calvo RA, Kearns DB. 2015. FlgM is secreted by the flagellar export apparatus in Bacillus subtilis. J Bacteriol 197:81-91.

46. Courtney CR, Cozy LM, Kearns DB. 2012. Molecular characterization of the flagellar hook in Bacillus subtilis. J Bacteriol. 194: 4619-29.

47. von Heijne G, Blomberg C. 1979. Trans-membrane translocation of proteins: the direct transfer model. Eur J Biochem 97:175-181.

48. Austen BM. 1979. Predicted secondary structures of amino-terminal extension sequences of secreted proteins. FEBS Lett 103:308-312.

49. Kyte J, Doolittle RF. 1982. A simple method for displaying the hydropathic character of a protein. J Mol Biol 157:105-132.

50. Tsirigotaki A, de Geyter J, Šoštarić N, Economou A, Karamanou S. 2017. Protein export through the bacterial Sec pathway. Nat Rev Microbiol 15:21-36.

51. Manoil C. 1991. Analysis of membrane protein topology using alkaline phosphatase and Bgalactosidase gene fusions. P61-75. In Tartakoff AM,ed. Methods in Cell Biology Vol. 34. Academic Press, San Diego, CA.

52. Chun SY, Parkinson JS. 1988. Bacterial motility: membrane topology of the Escherichia coli MotB protein. Science 239:276-278.

53. Stader J, Matsumura P, Vacante D, Dean GE, Macnab RM. 1986. Nucleoid sequence of the Escherichia coli motB gene and site-limited incorporation of its product into the cytoplasmic membrane. J Bacteriol 166:244-252.

54. Kojima S, Takao M, Almira G, Kawahara I, Sakuma M, Homma M, Kojima C, Imada K. 2018. The helix rearrangement in the periplasmic domain of the flagellar stator B subunit activates peptidoglycan binding and ion influx. Structure 26:590-598.

55. Santiveri M, Roa-Eguiara A, Kühne C, Wadhwa N, Hu H, Berg HC, Erhardt M, Taylor NMI. 2020. Structure and function of stator units of the bacterial flagellar motor. Cell 183:244-257.

56. san Millan JL, Boyd D, Dalbey R, Wickner W, Beckwith J. 1989. Use of phoA fusions to study the topology of the Escherichia coli inner membrane protein leader peptidase. J Bacteriol 171:55365541.

57. Ehrmann M, Boyd D, Beckwith J. 1990. Genetic analysis of membrane protein topology by a sandwich fusion approach. Proc Natl Acad Sci USA 87:7574-7578.

58. Cashel M, Freese E. 1964. Excretion of alkaline phosphatase by Bacillus subtilis. Biochem Biophys Res Commun 16:541-544.

59. Masters M, Donachie WD. 1966. Repression and the control of cyclic enzyme synthesis. Nature 209:476-7479. 
60. Hulett FM, Jensen K. 1988. Critical roles of $s p o 0 A$ and $s p o 0 H$ in vegetative alkaline phosphatase production in. J Bacillus subtilis Bacteriol 170:3765-3768.

61. Payne MS, Jackson EN. 1991. Use of alkaline phosphatase fusions to study protein secretion in Bacillus subtilis. J Bacteriol 173:2278-2282.

62. Varcamonti M, Marasco R, de Felice M, Sacco M. 1997. Membrane topology analysis of the Bacillus subtilis BofA protein involved in pro- $\sigma^{\mathrm{K}}$ processing. Microbiol 143:1053-1058.

64. Piazza F, Tortosa P, Dubnau D. 1999. Mutational analysis and membrane topology of ComP, a quorum-sensing histidine kinase of Bacillus subtilis controlling competence development. J Bacteriol 181:4540-4548.

65. Hulett FM, Kim EE, Bookstein C, Kapp NV, Edwards CW, Wyckoff HW. 1991. Bacillus subtilis alkaline phosphatases III and IV. Cloning, sequencing, and comparisons of deduced amino acid sequence with Escherichia coli alkaline phosphatase three-dimensional structure. J Biol Chem 266:1077-1084.

66. Linde M, Peterhoff D, Sterner R, Babinger P. 2016. Identification and characterization of heptaprenylglyceryl phosphate processing enzymes in Bacillus subtilis. J Biol Chem 291:1486114870.

67. de Jong WW, Zweers A, Cohen LH. 1978. Influence of single amino acid substitutions on electrophoretic mobility of sodium dodecyl sulfate-protein complexes. Biochem Biophys Res Commun 82:532-539.

68. Andersen KK, Oliveira CL, Larsen KL, Poulson FM, Callisen TH, Westh P, Pedersen JS, Otzen D. 2009. The role of decorated SDS micelles in sub-CMC protein denaturation and association. J Mol Biol 391:207-226.

69. Rath A, Blibowicka M, Nadeau VG, Chen G, Deber CW. 2009. Detergent binding explains anamolous SDS-PAGE migration of membrane proteins. Proc Natl Acad Sci USA 106:1760-1765.

70. Hansen JH, Petersen SV, Andersen KK, Enghild JJ, Damhus T, Otzen D. 2009. Stable intermediates determine proteins; primary unfolding sites in the presence of surfactants. Biopolymers 91:221-231.

71. von Heijne, G. 1989. Control of topology and mode of assembly of a polytopic membrane protein by positive charged residues. Nature 341:456-458.

72. Gao B, Lara-Tejero M, Lefebre M, Goodman AL, Galán JE. 2014. Novel components of the flagellar system in epsilonproteobacteria. mBio 5:e01349-14.

73. Barker CS, Meshcheryakova IV, Kostyukova AS, Samatey FA. 2010. FliO regulation of FliP in the formation of the Salmonella enterica flagellum. PLoS Genet 6:e1001143.

74. Barker CS, Meshcheryakova IV, Inoue T, Samatey FA. 2014. Assembling flagella in Salmonella mutant strains producing a type III export apparatus without FliO. J Bacteriol 196:40014011. 
75. Fabiani FD, Renault TT, Peters B, Dietsche T, Gálvez EJC, GUse A, Freier K, Charpentier E, Strowig T, Franz-Wachtel M, Macek B, Wagner S, Hensel M, Erhardt M. 2017. A flagellumspecific chaperone facilitates assembly of the core type III export apparatus of the bacterial flagellum. PLoS Biol 15:e2002267.

76. Karlinsey JE, Pease AJ, Winkler ME, Bailey JL, Hughes KT. 1997. The flk gene of Salmonella typhimurium couples flagella $\mathrm{P}$ - and L-ring assembly to flagellar morphogenesis. J Bacteriol 179:2389-2400.

77. Karlinsey JE, Tsui H-CT, Winkler ME, Hughes KT. 1998. Flk couples flgM translation to flagellar ring assembly in Salmonella typhimurium. J Bacteriol 180:5384-5397.

78. Aldridge P, Karlinsey JE, Becker E, Chevance FFV, Hughes KT. 2006. Flk prevents premature secretion of the anti-s factor FlgM into the periplasm. Mol Microbiol 60:630-642.

79. Hirano T, Mizuno S, Aizawa S-I, Hughes KT. 2009. Mutations in Flk, FlgG, FlhA, and FlhE that affect the flagellar type III secretion specificity switch in Salmonella enterica. J Bacteriol 191:3938-3949.

80. Yasbin RE, Young FE. 1974. Transduction in Bacillus subtilis by bacteriophage SPP1. J Virol 14:1343-1348.

81. Konkol MA, Blair KM, Kearns DB. 2013. Plasmid-encoded Coml inhibits competence in the ancestral 3610 strain of Bacillus subtilis. J Bacteriol 195:4085-4093.

82. Fujita M, Losick R. 2002. An investigation into the compartmentalization of the sporulation transcription factor sigmaE in Bacillus subtilis. Mol Microbiol 43:27-38.

83. Benson AK, Haldenwang WG. 1993. Regulation of sigma B levels and activity in Bacillus subtilis. J Bacteriol 175:2347-2356.

84. Eichenberger P, Jensen ST, Conlon EM, van Ooij C, Silvaggi J, González-Pastor JE, Fujita M, Ben-Yehuda S, Stragier P, Liu LJ, Losick R. 2003. The sigmaE regulon and the identification of additional sporulation genes in Bacillus subtilis. J Mol Biol 327:945-972.

85. Gibson DG, Young L, Chuang RY, Venter JC, Hutchinson CA ${ }^{\text {rd }}$, Smith HO. 2009. Enzymatic assembly of DNA molecules up to several hundred kilobases. Nat Methods 6:343-345. 


\section{FIGURE LEGENDS}

Figure 1. SwrB-YFP is functional and some swrB loss-of-function alleles are conditional.

Quantitative swarm expansion assays. A) SwrB is required for swarming motility: wild type (open circles, 3610) and swrB (closed circles, DS2509); B) SwrB-YPF is functional: $s w r B\left(s w r B^{+}\right)$(open squares, DS2522) and swrB (swrB-YFP) (gray squares, DS8161); C) Some swrB loss-of-function alleles are conditional: $\operatorname{swrB}\left(s w r B^{H 13 R}\right)$ (gray triangles, DS7606), swrB (swrB ${ }^{L 155 P}$ ) (open triangles, DS7783), $\operatorname{swrB}\left(\operatorname{swrB}^{F 51 S}\right.$ ) (gray diamonds, DS7782), $\operatorname{swrB}\left(\operatorname{swrB}^{L 48 S}\right.$ ) (open inverted triangles, DS7781), and swrB (swrB ${ }^{L 53 P}$ ) (gray inverted triangles, DS7669). Genotypes in parentheses indicate complementation constructs. Each line is the average of three replicates.

Figure 2. SwrB localizes as puncta that do not require the flagellar basal body. Fluorescence micrographs of YFP translationally fused to SwrB and inserted at the ectopic site in strains carrying a mutated swrB gene at the native locus and a mutation in the indicated gene, if any. Membranes were stained with the membrane stain TMA-DPH and false colored cyan. SwrB-YFP was false colored yellow. The following strains were used to generate these panels: wild type (DS8161), fliF (DK204), flhA (DK310), and fliP (DK235).

Figure 3. SwrB puncta rarely co-localize with flagellar hooks. Fluorescence micrograph of GFP translationally fused to SwrB and stained for flagellar hooks $\left(\mathrm{Flg}^{\mathrm{T123C}}\right)$ with a fluorescent malemide dye in a wild type background. Membranes were stained with the membrane stain TMA-DPH and false colored blue. SwrB-GFP puncta were false colored green. Hooks were stained with maleimide alexa fluor 592 and false colored red. The following strain was used to generate this panel: wild type (DS9404). 
796 Figure 4. The topology of SwrB positions the C-terminus in the cytoplasm. A) Colonies of strains containing the indicated fusion to lacZ on LB containing $1 \mathrm{mM}$ IPTG and the chromogenic substrate X-gal incubated overnight at $30^{\circ} \mathrm{C}$. $\varnothing$ indicates the parental strain that does not contain the lacZ gene. The following strains were used to generate the panels: $\varnothing$ (PY79), noTM (DK9023), motBTM (DK9041), and swrBTM (DK9042). B) Colonies of strains containing the indicated fusion to phoA on LB containing $1 \mathrm{mM}$ IPTG and the chromogenic substrate X-P incubated overnight at $30^{\circ} \mathrm{C}$. $\varnothing$ indicates the parental strain that does not contain the phoA gene. The following strains were used to generate the panels: $\varnothing$ (DK3843), noTM (DK8730), motBTM (DK9041), and swrBTM (DK9042). C) Topology prediction of SwrB inserted into the plasma membrane according to results in panels A and $\mathrm{B}$. The putative location of missense mutations outlined in Fig $6 \mathrm{~A}$ are indicated by red circles.

Figure 5. Non-functional alleles of swrB that produce stable gene products. A) Western blot analysis of whole cell lysates from the indicated genetic backgrounds probed with anti-SwrB and antiSigA primary antibodies. Black carets indicate antibody specific targets. Complementation constructs expressing the indicated alleles of $s w r B$ complements are listed above the black bar. The following strains were used to generate this panel with the complementation construct indicated in parentheses: wild type (3610), swrB (DS2509), swrB (swrB ${ }^{H 13 R}$ ) (DS7606), swrB (swrB ${ }^{L 48 S}$ ) (DS7781), $\operatorname{swrB}\left(\operatorname{swrB}^{F 51 S}\right)$ (DS7782), swrB (swrB $\left.{ }^{L 53 P}\right)$ (DS7669), swrB (swrB $\left.{ }^{L 155 P}\right)(\mathrm{DS} 7783) . \quad$ B) $\beta-$ galactosidase assays of swrA $P_{\text {hag }}$-lacZ transcriptional activity expressed in Miller Units in the indicated genetic backgrounds. The $\varnothing$ symbol indicates that no further genetic modification was included whereas "swrB" indicates the introduction of a $s w r B$ deletion mutation to the indicated genetic background. Complementation constructs expressing the indicated alleles of swrB complements are listed below the black bar. $\beta$-galactosidase values presented in Table S3. The following strains were used to generate this panel with complementation construct indicated in parentheses: $\varnothing$ (DS6332), swrB (DS6334), swrB (swrB $\left.{ }^{W T}\right)(\mathrm{DS6350}), \operatorname{swrB}\left(\right.$ swrB $\left.^{H 13 R}\right)$ (DS7513), 
$s w r B\left(s w r B^{L 48 S}\right)(D S 7443), s w r B\left(s w r B^{F 51 S}\right)(D S 7749), s w r B\left(s w r B^{L 53 P}\right)(D S 7244), s w r B\left(s w r B^{L 155 P}\right)$ (DS7750).

Figure 6. A mutation within the transmembrane domain abolishes punctate localization. A) Multiple-sequence alignment of SwrB from Bacillus subtilis (Bsub), Bacillus licheniformis (Blic), Bacillus vallismortis (Bval), Bacillus halodurans (Bhal), Bacillus atropheus (Batr), and Bacillus amyloliquefaciens (Bamy). Red circles indicate the location of a missense mutation that impairs SwrB function. "TM" and bracket indicate the location of the transmembrane domain. Fluorescence micrographs of YFP translationally fused to either the wildtype version of SwrB or SwrB containing the indicated single missense mutations. Membranes were stained with the membrane stain TMA-DPH and false colored cyan. SwrB-YFP false colored yellow. The following strains were used to generate these panels: wild type (DS8161), swrB swrB ${ }^{H 13 R}-$ YFP (DS8364), swrB swrB ${ }^{H 13 L}$ YFP (DK201), swrB swrB ${ }^{L 8 S_{-}}$YFP (DS8485), swrB swrB ${ }^{F 51 S_{-}}$YFP (DS8348), swrB swrB ${ }^{L 53 P}-Y F P$ (DS8484), swrB swrB ${ }^{L 155 P}-Y F P(D S 8483)$. 
Figure 1
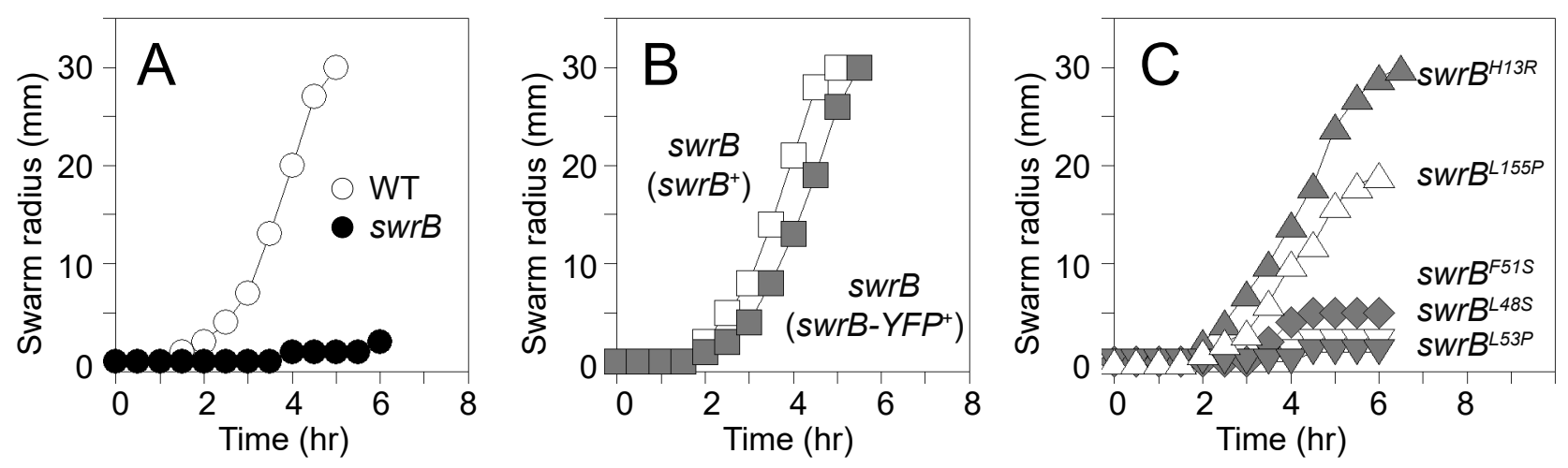
Figure 2

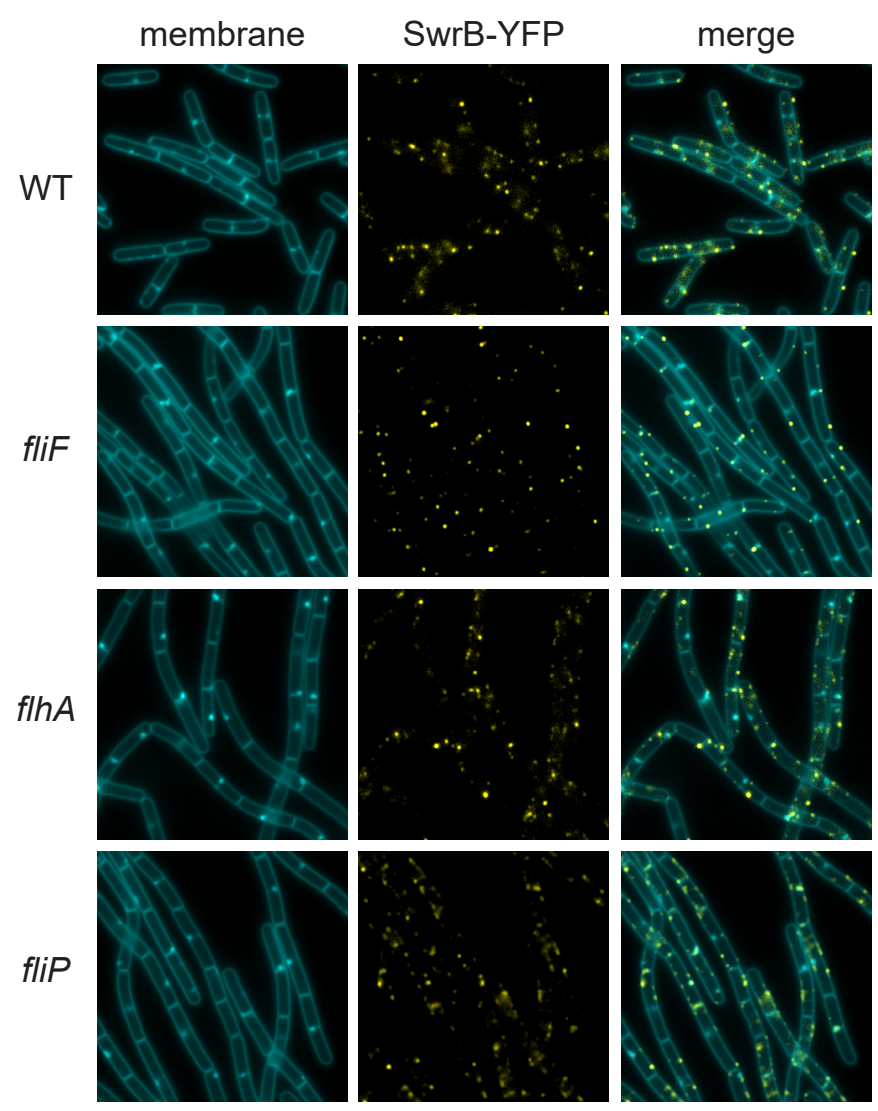


bioRxiv preprint doi: https://doi.org/10.1101/2021.04.30.442225; this version posted May 1, 2021. The copyright holder for this preprint (which was not certified by peer review) is the author/funder. All rights reserved. No reuse allowed without permission.

Figure 3

membrane

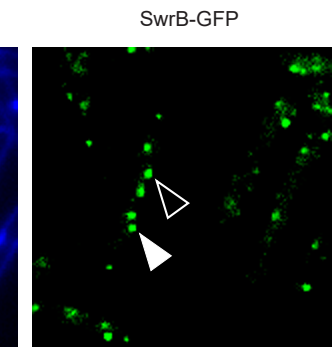

flagellar hooks
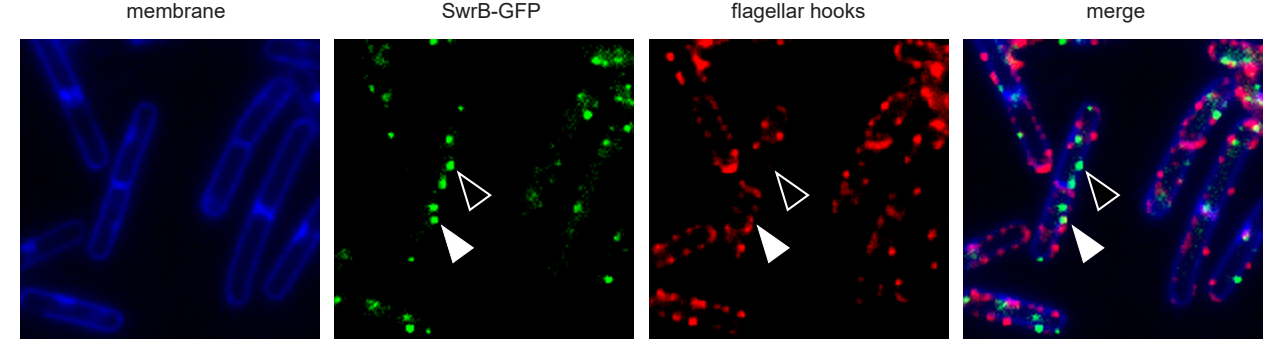
Figure 4

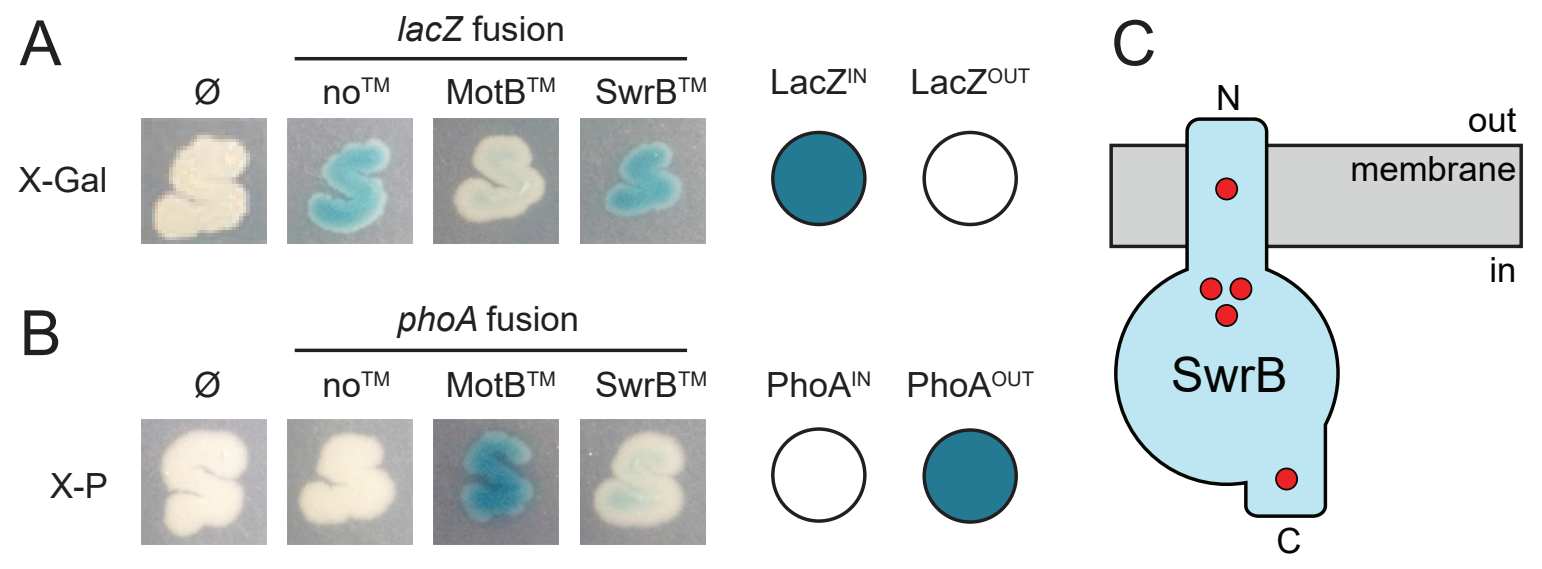


Figure 5

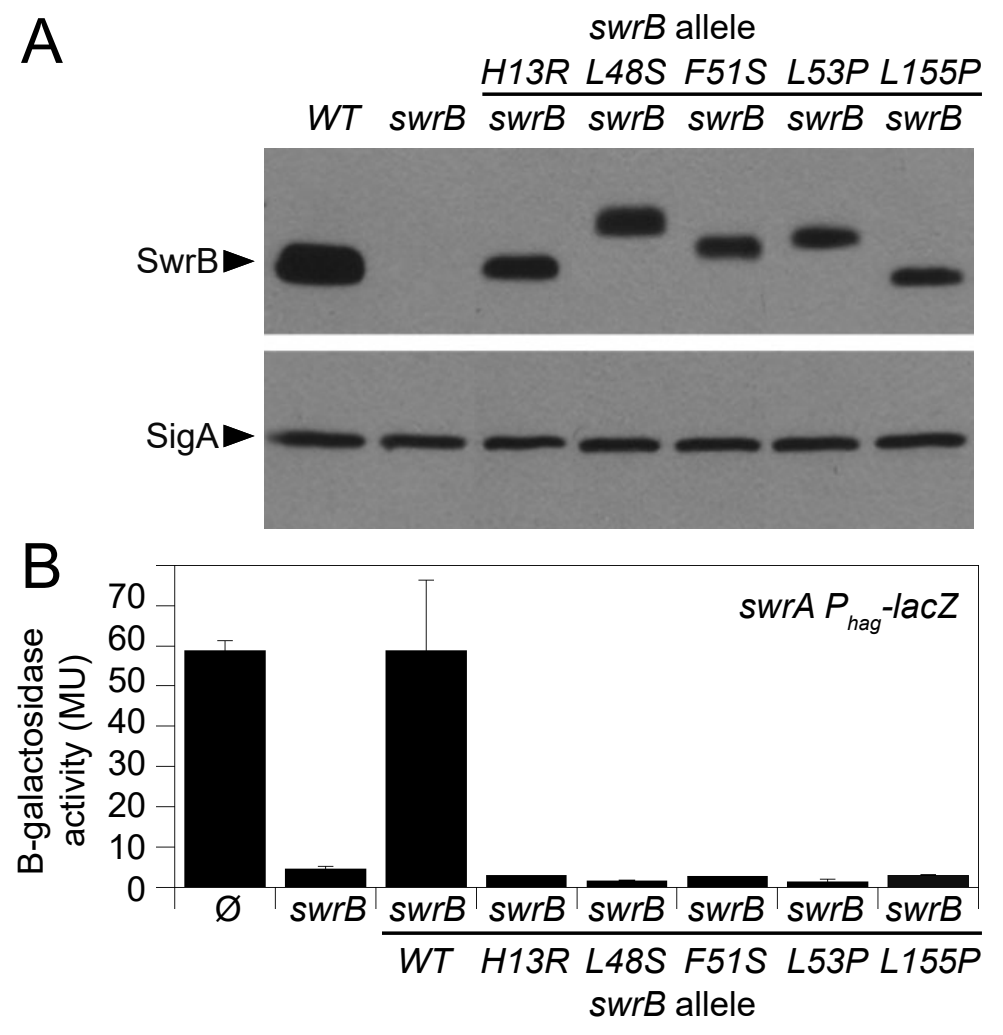




\section{Figure 6}

\section{$\bigcirc 00$}

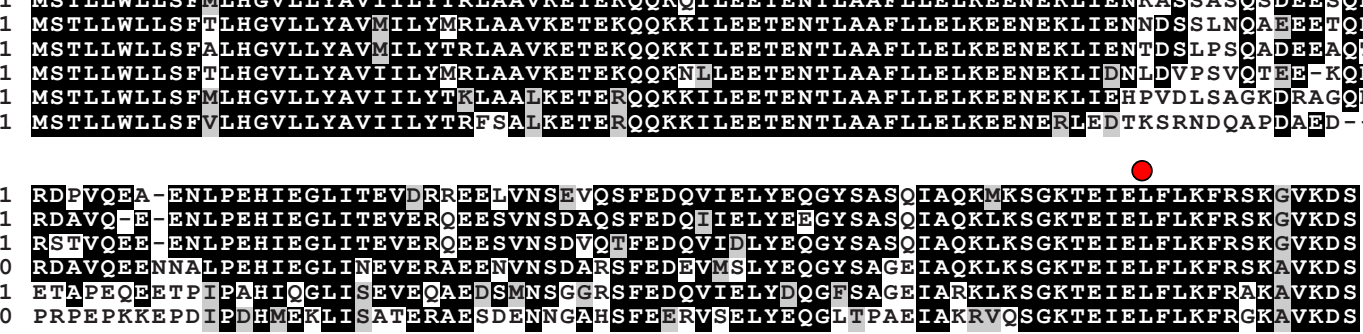

B

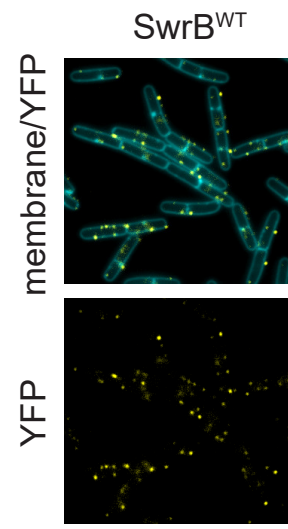

SwrB ${ }^{H 13 R}$
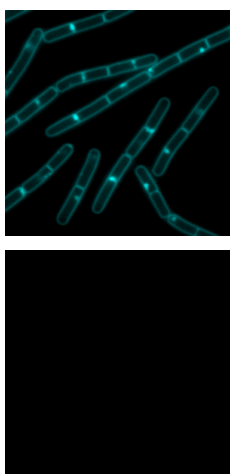

SwrB ${ }^{H 13 L}$
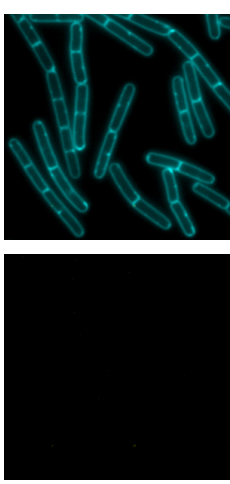

SwrB ${ }^{\text {L48 }}$
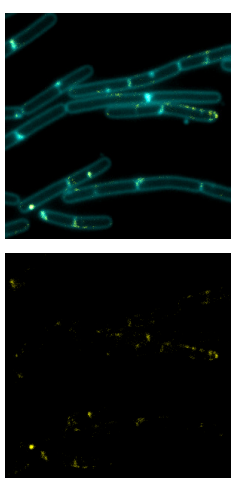

SwrB ${ }^{F 51 S}$
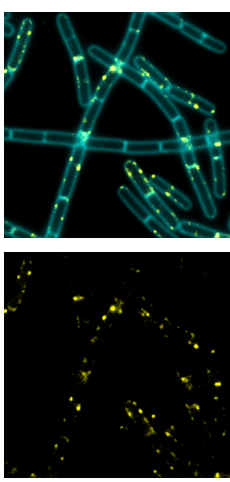

SwrB ${ }^{\llcorner 3}$

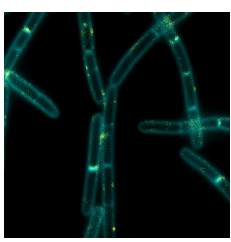

SwrB ${ }^{L 155 P}$

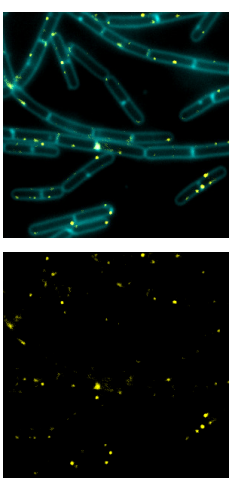

